\title{
Influence of Call Centers on Emerging Business Models and Practices
}

\author{
Ahmed O. Adeyemi ${ }^{1}$, Mohamad A. Saouli ${ }^{2}$ and Bhaskar Sinha, ${ }^{3, *}$ \\ ${ }^{1}$ Argosy University, Orange \\ California, USA \\ ${ }^{2}$ DeVry University, Long Beach \\ California, USA \\ ${ }^{3}$ National University San Diego \\ California, USA \\ *Corresponding author's email: BSinha [AT] nu.edu
}

\begin{abstract}
Call Centers have been an integral part of businesses operations, thereby providing organization contact points for the customers while facilitating changes and improvements of products and services offered by the organization. Call Centers give organizations the ability to extend their reach within their respective market space, which allows them to maintain lasting relationships with their environments, customers, and competitors providing time savings, cost savings, business continuity, strategic opportunities, sustainability, competitive advantage, and customer insight, on the products and services offered. As such, organizations are able to build Call Centers as integral business solutions, hence enhancing profitability and maneuverability within their market space. This study is conducted utilizing a phenomenological approach to qualitative research method that addresses (a) Innovation is one of the business models that create sustainable competitive advantage where organizations are gearing towards, to carve out or maintain market share (b) phenomenological approach used for this qualitative research (c) utilization of NVivo to create a thematic analysis of the results collected from interviews, case studies, observations, and other empirical studies (d) discuss the trends and impacts of call centers on business models and practices.
\end{abstract}

Keywords--- Demographic data, physical session, NVivo, Omni-channel, reflexivity, remote session, telematics, transferability, triangulation, voice portal, voice protocol, VOIP, War of Wires.

\section{INTRODUCTION}

Telecommunication has come a long way since discovering that voice can be transported over a string or wire to a form of ear and mouthpiece. There have been several innovative methods, which have progressed over the years and have resulted in several enhanced developmental ideas. Since this discovery, there has been a steady growth in the telecommunication industry. Telecommunication has been defined as a "War of Wires" [1] which is due to the interconnectivity of cables that form a path of communication from one point to another and to multipoint(s). In recent years the need for telecommunications to breach the gap between distance and timesaving is on the rise thereby decisions can be made instantaneously and globalization becomes more efficiently virtual, through synchronous and asynchronous connections. To that extent, there are other contributing factors to the development of telecommunication, which include internetworking that in the past ten years, have seen a high demand of migrating systems to follow the same path as the Internet. This follows the recent trend of converged network, which involves Voice over Internet Protocol (VoIP). VoIP has been the major development and is still currently trending in the telecommunication world; people are becoming more dependent on telephones and relying on their network systems to host their telecommunication/voice services. Businesses rely more on telephones to improve customer services (Contact/Call Centers), create a market share/space by being able to advertise over the phone (Tele-marketers), increase sales, and enhance products while creating better awareness [2]. Even emergency responders such as hospitals and 911 have adapted to this technology which has created ways to manage large amount of calls that route to the proper dispatch based on the location from the point of entrance/geo-location (GPS) [3]. Businesses adapting to this communication means, allow for open innovation which not only focuses on ways to advance the telecommunication industry, but it creates a way that people think (develop ways of integrating telecommunication into other 
systems) and allows room for innovation which in today's world, plays a significant role in the growth and transformation of how open innovation leads to defining business processes and procedures, profitability, revenue stream, and sustainability and technological development [4]. The statement about war of wires [1] is appropriate because it involves the interconnectivity between various cables to allow the full communication path from point to point. This led to the improvement in intranet and Internet technology which resulted in further advancement in several areas such as the technological emergence and embedded systems in the telecommunication industry. Over the past decade, the impact of telecommunication has steadily increased, starting from the way the military integrates and revolves its missions around telecommunication, and businesses are utilizing it as a method to generate income and creating expertise that has become essential for their operations. Telecommunication has come a long way from the days of using circuit switching (copper wire to route calls) to being in a converged network/packet switching (routing voice, data, and video over a fiber optic path). Though they are still some instances of circuit switching being utilized, the vast majorities of organizations (Automotive industry, industrial businesses, etc.) are moving towards reducing cost and optimizing the voice infrastructure. This new model is the key advantage of packet switching over circuit switching. Packet switching provides the opportunity to route and manipulate voice and data traffic; thereby traffic gets encapsulated at the sending end and de-encapsulated on the receiving end.

Businesses traditionally viewed telecommunication as a cost center due to the fact that it was not a revenue producing unit. But as time progressed, organizations and business leaders noticed the effectiveness of how telecommunication could improve their relationship with their customers, which lead to the development of the Contact/Call Center [5]. Contact/Call Center became a way that businesses generate profit by managing the other segments of Information Technology departments. Call center is the front door to a businesses and is the place where most crucial customer interactions take place [3]. Due to the high availability and value call center provides, it is noted as an integral part of how businesses operate creating a means for innovation, collaboration, outsourcing, sustainability and enterprise transformation, which are all part of major trends of today's business industry.

Call Centers came in existence with the thought of reducing face-to-face communication and to reduce cost of travelling for people. As a result of this, calls to a phone line became loaded in terms that heavy volumes of calls were coming in for the secretary and assistants, which resulted in, dropped and missed calls. However, with the advancement in telecommunication and computer technology, the Call Centers were developed to improve customer service procedures. Call Centers are changing the way companies communicate with customers and are a strategic asset in delivering exceptional service quality [6]. This technology offers businesses flexibility, ease of use, and functionality that brings together various forms of business models. Some of the Call Center technologies that businesses use, are deployment of computer controlled network, integration/merge of voice, data, video and image traffic, availability of high-capacity telecommunication links, development of call flow strategy, etc. Once businesses realized these technological applications enhance their business procedures, they started to apply them into all their models and many started outsourcing to other countries to maintain their technical solutions to their customers at a cheaper cost of labor.

\section{RESEARCH DESCRIPTION}

Innovation is an important element of business models to create sustainable competitive advantage that all organizations are gearing towards, to carve out or maintain market share [7]. As a result, businesses look to enhance their productivity and efficiency by increasing customer services and creativity: which overall attracts new customers while retaining the old ones [8]. Telecommunication has been an integral part of this process. Organizations are able to adapt several telecommunication applications such as the Call Center and virtualization which not only helps cut cost, but they also help generate additional revenues while creating direct relationships between the business operations: Customer Service Representative (CSR), development, production, and quality assurance. This multi-facet relationship allows the organization to create a structure and practice that intersects all areas of business. Integrating these areas have resulted in high level of innovation, which the telecommunication industry have adapted as an open innovation model. This model has significantly allowed people to tie in systems, thereby a single solution can be deployed to retrieve customer information, rather than branching out to other systems which then creates dependability [9]. Businesses are able to develop better processes that become more efficient and create ideas that integrate telecommunication in other areas of business. An example is in the automotive industry. Hyundai developed a system known as BlueLink, which is provided to the customer as a safety and security feature that allows the customers to connect to Call Centers. This feature is activated via a simple push of a button or automatically in case of an accident. By Hyundai adapting this technology, it not only assists the customers having a sense of safety but it also creates a new channel of revenue generation, while focusing more on sustainable competitive advantage. This creates a standard within the automotive and telecommunication industry, customer's satisfaction and safety, and an open innovation model. 
Trends in the past have been leading to industries being able to communicate using several methods of telecommunication systems but most importantly, being able to respond to their customers' needs at any given time of the day. With the utilization of Call Centers, businesses have been able to build this environment were instead of customers speaking to an automated machine, they are able to connect to real people who can lead to the resolution of their complaints, which overall satisfies the customer's needs rather than speaking to a machine that cannot connect with the customer. This topic aims to uncover the impact of how these systems help retain the customer satisfaction, attract new ones, aide businesses in defining its practices and build a business model that aims at gaining competitive advantage [10]. This research design comprises of the business operations, call center, agents and supervisors, developers, and business leaders. By this, this effort brings together how these components fit together and provide an insight into how the trends in telecommunication affect business models, operations, and enhance business processes. This study provides an insight into how businesses make decisions revolving around technology, more specifically in the telecommunication industry. Businesses have been able to adapt some of the applications of telecommunication, such as the call center, which brings the customers closer to the product and helps organizations address the critique on their product.

This study is significant because with technology enhancements, organizations are able to make smart decisions which allows them to save money and cut associated costs, while expanding the customer base. This is accomplished by being able to reach their customers that have an existing product and provide support to the product by having a Omni-channel mechanism (method that provides an all in one platform for agents to execute their task) which in today's telecommunication field chat, call centers, web pages and surveys are integrated to provide a complete solution and customer support. By doing this, businesses are able to identify problems within their products, improve product features, help dissatisfied customers, and attract new customers. This paper focuses on the impact of telecommunication on business. In order for businesses to succeed, they need to adapt to new technologies and applications that will enhance the business models and practices. Telecommunication applications are one of the recent trends introduced in business. The two areas analyzed and presented in this paper are: (1) What are the impacts of telecommunication application used in Call Center Omni-channel environment on business models and practices? and (2) How does the impact of call centers help organizations make business decisions? All Call Centers in this study are in the United States with company headquarters also in the United States.

\section{RESEARCH METHODOLOGY}

Choosing the research methodology is important as it helps understand how the data is collected and the underpinning of the collected data. It is important to select the appropriate research methodology because it helps create an understanding of the purpose of the research bringing to light the topic of choice. The methodology selected for this topic is qualitative methodology. This creates a conceptual understanding and description of the impact of telecommunication on business models and practices. By using this methodology, observations are related to trends, customer's impact, and product enhancements that comes about as a result of how business adjusts to the impacts.

The methodology used for this research is qualitative analysis. Within qualitative analysis, the researchers used phenomenology theory. A phenomenological study is one that focuses on descriptions of what people experience and how it is that they experience what they experience [11]. By employing the concept of phenomenology, the researchers employed a general perspective that would capture the experiences and observation of people within the study. More specifically, phenomenology is used to explore an aspect of businesses which organization in the bigger scheme of operations overlook the impact of call centers on business operations. The researchers chose this methodology due to the nature of qualitative research, which includes sociological and anthropological approaches that often provide data from natural settings [12]. By this, the researchers utilized case studies, observation, and interviews to collect data. Interviews contained 10-15 questions, each covering an open-ended research question and follow-up questions. The selected methodology is appropriate for this research because every customer environment is unique and with technology acting as a change agent, some organizations advance with the technology to enhance their operations and provide flexibility for their business. Qualitative analysis exposes some of the call center trends.

The population of this study included participants comprising of Call Center agents and supervisors, developers from engineering departments, quality team, and business managers. The participants were selected randomly to avoid biased conclusions. The randomness included the shift, skill groups within the Call Center, and the different tiers of support provided. Selecting these groups provided variability in the information being retrieved to reflect how the trends are applied and the communication between the teams involved along with providing visibilities on how the business decision makers get their information to make sound judgments based on what is relayed to them. The selected population was informed of the research details and consent to participate in the study was obtained. 


\section{RESULTS AND FINDINGS}

Results for this research were obtained using qualitative methodology to explore the impact of telecommunication on business models and practices. This section presents the analysis of results in form of demographic information and the results of interviews conducted with participants including agents, supervisors and managers. The data is analyzed using open, axial and selective coding. Major themes are identified and their interrelationships are examined in light of existing literature. Participants were distributed with respect to demographics, age, gender, income level, and locations. This distribution is shown in Table 1.

\begin{tabular}{|c|c|c|c|}
\hline \multicolumn{4}{|c|}{ PARTICIPANT DATA } \\
\hline \multirow{7}{*}{ DEMOGRAPHICS } & TOTAL & 40 & $100.0 \%$ \\
\hline & Health Care & 3 & $7.5 \%$ \\
\hline & Insurance & 4 & $10.0 \%$ \\
\hline & Service/IT & 3 & $7.5 \%$ \\
\hline & Clothing/Shoes & 9 & $22.5 \%$ \\
\hline & Automobile & 7 & $17.5 \%$ \\
\hline & Other & 14 & $35.0 \%$ \\
\hline \multirow{6}{*}{ AGE } & TOTAL & 40 & $100.0 \%$ \\
\hline & $<18$ & 0 & $0.0 \%$ \\
\hline & $18-29$ & 7 & $17.5 \%$ \\
\hline & $30-44$ & 14 & $35.0 \%$ \\
\hline & $45-59$ & 16 & $40.0 \%$ \\
\hline & $>=60$ & 3 & $7.5 \%$ \\
\hline \multirow{3}{*}{ GENDER } & TOTAL & 40 & $100.0 \%$ \\
\hline & Male & 17 & $42.5 \%$ \\
\hline & Female & 23 & $57.5 \%$ \\
\hline \multirow{12}{*}{ INCOME } & TOTAL & 40 & $100.0 \%$ \\
\hline & $\$ 0-\$ 9,999$ & 0 & $0.0 \%$ \\
\hline & $\$ 10,000-\$ 24,999$ & 4 & $10.0 \%$ \\
\hline & $\$ 25,000-\$ 49,999$ & 5 & $12.5 \%$ \\
\hline & $\$ 50,000-\$ 74,999$ & 6 & $15.0 \%$ \\
\hline & $\$ 75,000-\$ 99,999$ & 2 & $5.0 \%$ \\
\hline & $\$ 100,000-\$ 124,999$ & 4 & $10.0 \%$ \\
\hline & $\$ 125,000-\$ 149,999$ & 5 & $12.5 \%$ \\
\hline & $\$ 150,000-\$ 174,999$ & 7 & $17.5 \%$ \\
\hline & $\$ 175,000-\$ 199,999$ & 3 & $7.5 \%$ \\
\hline & $>=\$ 200,000$ & 2 & $5.0 \%$ \\
\hline & No Response & 2 & $5.0 \%$ \\
\hline \multirow{10}{*}{ LOCATION } & TOTAL & 40 & $100.0 \%$ \\
\hline & New England & 14 & $35.0 \%$ \\
\hline & Mid-Atlantic & 6 & $15.0 \%$ \\
\hline & East North Central & 3 & $7.5 \%$ \\
\hline & West North Central & 3 & $7.5 \%$ \\
\hline & South Atlantic & 0 & $0.0 \%$ \\
\hline & East South Central & 0 & $0.0 \%$ \\
\hline & West South Central & 6 & $15.0 \%$ \\
\hline & Mountain & 8 & $20.0 \%$ \\
\hline & Pacific & 0 & $0.0 \%$ \\
\hline
\end{tabular}

Table 1. Participant Data 
Open coding was performed and general codes were assigned to the transcripts. Axial coding was done by linking the open codes and establishing their associations. After that themes were separated by means of selective coding to draw conclusions for this research.

Conclusions from the responses of the participants are that the Omni-Channel environments are creating significant changes in ways businesses are carried out. Businesses are increasingly incorporating modern technologies in delivering products and services, and with enhancing interactions with consumers. The participants reported that they are working in more technologically advanced business settings facilitating ease of response to consumer inquiries and help resolve their complaints in an effective manner. Businesses are relying on new ways to manage consumer issues such as using Standard Operating Procedures (SOP) and Omni-channels that enable the call center agents to manage more consumers in a timely manner. Furthermore, it reduces the burden on agents and allows them to offer more empathetic services and take ownership of issues till they are resolved. This ensures a complete and satisfactory conflict resolution. The work load is reduced and staff can manage their work by following flexible timings, they have computerized record of consumer information along with the organizational standard guidelines to deal with issues, and this enables the call center agents to respond to consumers in an effective and accurate manner. In addition to this businesses are becoming more consumer-centric due to the adoption of Omni-Channel environments in telecommunication. These systems enable the businesses to have a detailed understanding of issues faced by consumers and getting their inputs and suggestions. Building on the data received by consumers, the businesses are better equipped to amend the products and services in accordance with needs and demands of consumers. This allows business to have more satisfied consumers by fulfilling their needs in the manner they want and become a consumer focused business. All this have become possible due to the adoption of latest call center technologies.

Call centers are acting as a mechanisms that link the consumer feedbacks to top management, which is incorporated in the process of making decisions. Businesses are increasingly using feedbacks from consumers received from call centers in order to make their products and services better according to the needs of consumers. Businesses are more aware regarding the changing consumer behaviors and their needs and demands by getting their first-hand input that are provided as suggestions and feedback at call centers. These inputs and feedbacks are incorporated in the process of product and service improvements. This has led to better communication between business leadership and call center staff, as the input and feedback of consumers are transferred to upper management by means of Customer Service Software, reports, meetings, and representations of results in graphical formats. Collaboration between agents, supervisors, and leadership are significantly improved in all types of businesses. Issues are identified in a timely manner and reported to top management efficiently. Items of high importance are communicated effectively to supervisors that are specifically concerned with that particular issue. Moreover, the regular reporting is done to executive leadership in this regard; the trend reports are created based on consumer feedback and inputs. They are presented to senior management on regular bases. Responses from participants of this research clearly shows that top management is paying more attention to call centers incorporating modern technologies as they have realized the advantages it offers in enhancing consumers satisfaction and business success. Responses from participants clearly shows that business leaders are increasingly giving more importance to call centers as an effective tool for better consumer interaction, feedback, conflict resolution, and inputs that allows business to act in accordance to changing consumer demands and make the products and services in accordance to their needs, thus resulting in more satisfied consumers. These are key components of a business success.

Trend is shifting towards the integration of innovative voice protocols that are aided by video technologies. Business organizations are considering this trend to adopt this latest advancement in call center settings. This will allow the business to have better technological edge and improve customer experience. The participants reported that businesses manage their workforce and technologies that are used in delivering call center services according to the latest trends. The environment of call center is changed by making it more flexible, allowing the staff to work from home, and manage the office space effectively as they adopt the advanced Interactive Voice Response (IVR) options to manage the work load. These innovative voice protocols are leading to a flexible work environment and an ability to better resolve the consumer issues in context of changing work environments. It was identified by the research respondents that call centers employing innovative technologies are able to incorporate the input from consumers as well as the reports generated by call center staff regarding the number of complaints that are received, how the issues were resolved, and the surveys that are conducted for the purpose of getting consumer view-points regarding provision of products and services. In addition, decisions for taking effective actions for better consumer services are more efficient. Business progress is measured in terms of the number of calls that are received regarding a particular issue and how effectively and efficiently that issue gets resolved. Use of modern voice protocols was found to render various advantages to business organizations. It was identified by the participants that use of modern technology is one of the elements that cause the agents in call centers to manage their work in efficient way as large volumes of calls can be managed in less time. The agents have more time to handle the most critical issues rather than spending time on routine ones, thus solving customer issues in more effective and timely manner. 
Several other advantages were identified from the responses that are caused by innovative voice protocols and OmniChannels in terms of better use of information and dealing with consumer complaints in a timely manner. Using OmniChannel enables better management and handling of historical reports thus making the interaction with consumers better. Trend identifications also becomes better while the job of call center agents are simplified. This makes the delivery of services more accurate and error free and improves the overall speed of dealing with consumers and resolving their issues. An important advantage of adopting Omni-Channel and innovations in voice protocol is a significant improvement in making business more profitable. Using these technologies reduces the costs of operations, thus having a positive impact on the business bottom line. Such advantages that enhanced effectiveness and efficiencies of operations translate into better issue resolution and better customer services and satisfaction. When consumers are satisfied with the organizational services and products they continue their business relations, and this invariably results in increased profits. The seamless operations resulting from better technological advancements are one of the main sources of consumer satisfaction. When customers are satisfied, not only do they continue their business relationship with the organization, but they can also become the ambassadors of the organization on social media and other means of helping the brand Upper management places high priority on call centers by putting the latest technologies in place for seamless operations.

\section{CONCLUSIONS}

The aim of this study was to examine the manner in which modern business organizations are using technological advances in order to improve product and service delivery. This research specifically examined the advancement and technological development in call center settings in the telecommunication sector. Use of modern voice protocols and OmniChannel has brought changes in the manner consumers are dealt with. Adopting modern telecommunication techniques have allowed businesses to create better and closer association with customers [13]. Getting consumer feedback is fast and timely and keeps the business informed about the consumer complaints, feedback, and demand, allowing management to make decisions accordingly. This has allowed the business organizations to amend and improve their products and services to meet the changing consumer demands. Most businesses around the world are adopting multiple digital channels to have contact with consumers [14]. By becoming more consumer-centric, the business can attain competitive edge building on the modern telecommunication technology. This has significant impact on the business models, as more flexible, innovative, and consumer focused business models are developed based on innovative telecommunication voice protocols. Enhanced competition and availability of numerous communication channels have enhanced the importance of investigating this relationship. Consumers might initiate the purchase procedures from a digital or physical channel, but still they have an array of choices to proceed further till the completion of purchase process [15].

In the past decade, businesses have seen various developments in telecommunication technologies that have allowed the call centers to maintain close personal relationship with consumers rather than mere machine interactions. This has led to better customer attraction, retention and satisfaction, and allowed organizations to develop business models aimed at attaining competitive advantage [10]. Given the importance of modern telecommunication techniques this research examined the extent to which use of innovative telecommunication technologies is having impact on business operations, its work processes, and ultimately, on the success of business models that enables the organization to attain competitive edge. The use of "innovations of voice protocols" is attaining importance as one of the most important medium of dealing with consumers and managing effective communication with them [16]. In addition to this the use of multiple channels to connect with consumers is also a rising trend that has enhanced the importance of investigating Omni-Channel environments in call center settings [17]. All these elements triggered the present investigation to examine the link of modern telecommunication advances on business. The investigation in this research is focused on the application of telecommunication advancements such as Contact/Call Center, Interactive Voice Recognition, and Customer Voice Portal, and their influence on business. Furthermore, this investigation highlights the advantages of how using such technologies in that capacity is helping organizations make business decisions and enhance their product.

An interpretivism paradigm of research was adopted along with use of inductive approach [18]. Interviews were carried out with call center agents, supervisors, and business leaders in order to investigate the research issues. The interviews were recorded, transcribed, and open coding was done followed by axial and selective coding. This resulted in the emergence of main themes inkling the impact of telecommunication application used in Call Center Omni-channel environments on business model and practices, the role of agents, supervisors and executive leadership in understanding how the business changes its method of approach in order to enhance its products and provide a better customer experience. Another important theme included impact of innovations of voice protocols/managers impact effectiveness of call center applications in the telephone industry. This theme included discussion of impact of telecommunication innovation of business defects, increased profits, identification of trends, and using this data to make business decisions. 
The first theme dealt with the impact of telecommunication applications used in Call Center Omni-channel environments on business models and practices. It was revealed by the viewpoints of participants that Omni-Channel environment is creating a lot changes in ways business is carried out. Businesses is incorporating modern technologies in delivering products and services, and enhancing interactions with consumers. The participants reported that now they are working in more technologically advanced business settings in which it is easy to respond to consumer inquiries and resolve their complaints in an effective manner. This is consistent with the existing literature that states the shifting of business trends toward "OmniChannel" services that comprise of delivering business services in a seamless manner that enables consumer to have "integrated shopping experience". Organizations are relying on call centers and telecommunication technologies in order to deliver efficient and seamless services to attain competitive advantage and remain ahead of their rival firms [19]. It was found that Omni-channels have allowed business organizations to employ SOP and multiple channels. Due to this the efficiency and effectiveness have increased significantly, as the call center agents have less burden and they can give more time to deal with consumers support. This allows them to be empathic and resolve the complaints complete in less time period. Omni-Channels allow efficient and in-time service delivery and consumer contact that allows business to attain competitive advantage [14]. In addition to this, Omni-Channel environments allow businesses to have enhanced consumer focus. It facilitates incorporation of consumer advice and concerns and enables businesses to develop deep insight into the consumer behaviors. This allows better product and service development according to consumer needs and offer personalized services to keep the consumers satisfied. This is consistent with the arguments that Omni-Channels are one of the major sources for businesses to attain competitive advantage in the marketplace [20].

The second theme that came to surface by the views of respondents was the use of Omni-Channel environment and modern voice protocols in decision making - decisions that result in enhanced profits and satisfied consumers. It is found that better decision-making and satisfied consumers are prerequisite for business success and profit [21]. Same results were found in the similar research studies that narrated the use of modern technology, close consumer interactions, and incorporation of business trends in decision making. The use of voice management strategies by using internet protocols has significant impacts on the ay businesses are managed and operated. This consistent with Dean's findings in his article titled: The impact of customer orientation of call center Employees on customers' Affective Commitment and Loyalty [22] that adoption of modern telecommunication technology allows the business operations to be more effective. He asserted that this is due to better and closer interactions with consumers relying on innovative technologies used for voice transmission. When these technological advancements are used in call centers the employees become more productive by performing various tasks simultaneously in less time. This causes less work burden and better accuracy by reduction in duplication of efforts, less chances of human errors, and allows employees to manage their work in a flexible manner. It was reported by majority of participants that incorporation of consumer feedback allows them to have better information regarding the changing consumer attitudes and the points of consumer dissatisfaction. Based on this data businesses devise policies to make the products and design services in a way that is according to the needs and demands of consumers as customer satisfaction is prime element of business success and profitability [23]. When a business has the ability to meet consumer needs, reduce product defects, resolve consumer complaints, and offer them efficient services, the result is increased loyalty and satisfaction [24], which ultimately leads to better profits [25].

These results are also supported by the findings of Timm [26], who asserted that a lot of changes have occurred in services sector, specifically telecommunications that have made consumer interaction more important. This situation has also increased the competitive pressure on organizations to keep their technologies up to date. The trend of linking information technology and telecommunication is on the rise. The overall cost of production is reduced by implementation of modern technology and voice protocols that also enables businesses to have reduced cost of operation and have a positive impact on their bottom lines. Participants reported that the use of modern telecommunication is enabling their organizations to have efficient and effective operations, reduced products defects, better complaint resolution, and satisfied consumers. It was also reported that there is an increased trend in profitability since the business have adopted innovative voice protocols and OmniChannel environment. Previous research studies have also examined the positive link in adoption of modern technology in telecommunication with enhanced business profits [27-28]. All respondents reported that implementation of Omni-Channel and innovation in voice protocols is leading the business organizations to have better interaction with consumers, resolve their issues in effective and timely manner, incorporating firsthand information for trend analysis and making decisions to improve quality of products and services. This allows the call center staff to have less work load, easy way to deal with consumer issues in accurate manner, having low operational costs and delivery of products and services to be in accordance with consumer demands. This has shifted the business toward more flexible, efficient, and consumer focused business model that enhances its profitability. 


\section{FURTHER RESEARCH OPPORTUNITIES}

This study primarily explored Call Centers in the United States but within certain organizations. Organizations were selected due to their accessibility thereby only limited participants were available. As a result of these factors, further study could be conducted on a larger sample within and outside the United States to better understand the impact of call centers and how organization models the responses of their call centers to their business practices. In addition, as voice protocol expands and becomes more integrated and defined within organizations, it facilitates more standardization within the industry thereby call centers would be built in similar fashion and operate similarly within the standards established for particular industries.. This would provide additional insight as to how call center operations and business operations are integrated, thereby allowing the researcher to examine how call center operates as a business and its effectiveness in how it promotes customer retention, marketing, and profitability in a larger organization operations. The recommendation for further studies are: (a) How does business operations and call center operations align within an organization's overall concept of operation, (b) how can telecommunication protocol be standardized within organizations with the ever changing technology, (c) how does the integration of call centers in United States differ from other countries outside the United States, (d) what factors do businesses consider when adapting call centers as a strategy to maintain customer retention, customer corporate social responsibilities, marketing, customer connection, outreach, and integration of new technology such as big data, digitalization/digital transformation, and cloud computing, and (e) How does this analysis check with other organizations when the call centers are in-house versus when they are outsourced to third-party? Finally, one could extend the study conducted by Dzuba [29] to further explore call center management and how it relates to business organizations that utilize this method as a process within their practices.

\section{BIBLIOGRAPHY}

[1] Deur, J. (1999). Trends in Telecommunications. Vital Speeches of the Day, 65(23), 728

[2] O'Brien, J. and Kok, J. (2006). Business Intelligence and Telecommunication Industry: Can Business Intelligence Lead to Higher Profits? South African Journal of Information Management, 8 (3).

[3] Reynolds, P. (2010). Call Center Metrics: Best Practice in Performance Measurement and Management to Maximize Quitline Efficiency and Quality. North America Quitline Consortium (NAQC).

[4] Birudavolu, S. and Nag, B. (2011). A Study of Open Innovation in Telecommunication Services: A Review of Literature and Trends, IIFT Working Paper Series, No. EC-11-09. Retrieved from http://cc.iift.ac.in/research/Docs/WP/09.pdf.

[5] Searcy, T. (2007). Call Center Problems Go Global._Direct Marketing News (DMS). Retrieved http://www.dmnews.com/call-center-problems-go-global/article/95989/

[6] Marr, B. and Neely, A. (2004). Managing and Measuring for Value: The Case of Call Centre Performance. Retrieved from https://dspace.lib.cranfield.ac.uk/bitstream/1826/1221/1/callcentreperformance.pdf

[7] Porter M.E. (2002). Competitive and Antitrust. A Productivity-Based Approach. Harvard School of Business. Retrieved from http://www.hbs.edu/faculty/Publication\%20Files/053002antitrust_06eae678-b707-457c-b13918c38e45e786.pdf

[8] Van Bennekom, F.C. (2002). Customer Surveying: A Guidebook for Service Managers. Customer Service Press.

[9] Zhu, K., Kraemer, K.L., and Xu, S. (2006). The Process of Innovation Assimilation Firms in Different Countries: A Technology Diffusion Perspective on E-business. Management of Science, 52(10), 1557-1576

[10] Powell, T.C., and Dent-Micallef, A. (1997). Information Technology as Competitive Advantage: The Role of Human, Business, and Technology Resources. Strategic Management Journal, 18(5), 375-405

[11] Patton, M.Q. (1990). Qualitative Evaluation and Research Methods (2nd Ed.). Newbury Park, CA: SAGE.

[12] Bugday, S. (2012). Grounded Theory Design in Qualitative Analysis. Retrieved from http://www.slideshare.net/SehribanBugday/grounded-theory-11487784

[13] Salomo, S., Steinhoff, F. and Trommsdorff, V. (2003). Customer orientation in innovation projects and new product development success - the moderating effect of product innovativeness. International Journal of Technology Management, 26(5/6), p.442.

[14] Blok, E. (2016). Telecommunications - a sector in transformation. EY.com. Retrieved 21 July 2016, from http://www.ey.com/Publication/vwLUAssets/ey-global-telecommunications-study-navigating-the-road-to2020/\$FILE/ey-global-telecommunications-study-navigating-the-road-to-2020.pdf

[15] Wang, C., Huang, Y., Chen, C., and Lin, Y, (2006). The influence of customer relationship management process on management performance: The International Journal of Organizational Innovation

[16] Golhar, S. (2016). Voice over Internet Protocol (VoIP) Based IP PBX System Design. IJSR, 5(2), 1380-1385. http://dx.doi.org/10.21275/v5i2.14021604 
[17] Yang, C., Trimi, S., and Lee, S. (2016). Effects of telecom service providers' strategic investments on business performance. Industrial Management and Data Systems, 116(5), 960-977. http://dx.doi.org/10.1108/imds-08-20150350

[18] Schutz, A. (1962). Collect Papers, Volume 1, The Hague, Martinus Nijhoff. See in particular: "Commonsense and scientific interpretations of human action" pp. 3-47; "Concept and theory formation in the social sciences" pp. 4866; "On multiple realities" pp. 207-259.

[19] Esteban, L. (2015). From lineal attribution modeling to Omni channel contribution modeling: How to use marketing attribution and optimization for SEO, Social Media, SEM and other channels. J Account Mark, 04(03). http://dx.doi.org/10.4172/2168-9601.c1.001

[20] Martin, R. (2016). The key to Omni channel success is customer-centricity. [online] Pitney Bowes. Available at: http://www.pitneybowes.com/us/global-ecommerce/case-studies/the-key-to-omni-channel-success-is-customercentricity.html [Accessed 10 Aug. 2016].

[21] Shoretel.com. (2016). Advantages of Using VoIP Technology for Your Business. [online] Available at: https://www.shoretel.com/advantages-using-voip-your-business [Accessed 10 Aug. 2016].

[22] Dean, A. M. (2007). The impact of customer orientation of call center Employees on customers' Affective Commitment and Loyalty; Journal of Service Research, Volume 10, no 2. Pp. $161-173$

[23] Nunn, L., McGuire, B. and Crowe, B. (2011). Measuring the Benefits of Voice-Over-Internet Protocol (VOIP). RBIS, 13(4).

[24] Bendoly, E. (2005), "Online/In-Store Integration and Customer Retention", Journal of Service Research, Vol. 7 No. 4, pp. 313-327.

[25] Brynjolfsson, E., and Rahman, J. (2013), "Competing in the Age of Omni channel Retailing", MIT Sloan Management Review, Vol. 54 No. 4, pp. 23-29.

[26] Timm, P.R. (2008). Customer Service: Career Success through Customer Loyalty, Fourth Edition, USA: Pearson Prentice Hall.

[27] Müller, G. (2005). Success factors and impacts of mobile business applications: Results from a mobile eprocurement study. Wirtschaftsinf, 47(4), pp.298-299.Irwin, D. (2007). Automatic Crash Notification and Vehicle Telematics Technical Information Document (TID). National Emergency Number Association (NENA) and NonTraditional Communication Committee. Retrieved June 18, 2016 from https://c.ymcdn.com/sites/www.nena.org/resource/collection/91E03A3A-B334-4EB6-9205E25BBF6AF8E7/NENA_07-504-v1_Collision_Notification_and_Telematics_Information.pdf

[28] Aksin, Z., Armony, M., and Mehrotra, V. (2007). The Modern Call Center: A Multi-Disciplinary Perspective on Operations Management Research. Retrieved September 26, 2013 from http://citeseerx.ist.psu.edu/viewdoc/download?doi=10.1.1.129.4795\&rep=rep1\&type=pdf

[29] Dzuba, R. (2015). Exploring the Experiences of Call Center Employees Regarding Business Scripting. Walden Dissertation and Doctoral Studies. Retrieved August 11, 2016 from http://scholarworks.waldenu.edu/cgi/viewcontent.cgi?article=1575\&context=dissertations 